\title{
Creativity, plasticity, quality: on the emergence of a new food offering in Paris $^{1}$
}

\begin{abstract}
This paper presents the conditions of the recent emergence of quality fast food restaurants in Paris. Rather than being a radical innovation, the development of this new form of restaurants can be understood through the concept of path plasticity. That is innovation and change occurring within a well-established institutional setting of technology/knowledge development path (Paris catering services in our case) without necessarily breaking out of the path in question. Quality fast food has developed relying on the existing structures of the catering production system while creating bridges between two kinds of restaurants: traditional tasty and fine cuisine and fast food way of eating.
\end{abstract}

Keywords: innovation, quality, path plasticity, path dependency, creativity, fast food, Paris

\section{Introduction}

The increase of urban demand for high quality lunch fast food (quality in terms of products e.g. organic, certified food; e.g. freshness, inventiveness, diet) has recently given rise to new lunch suppliers such as shops, restaurants, delis, which mix food, culture, health, fanciness, and often sophistication. If these restaurants are still of a very small number in proportion to standard fast food restaurants their number are increasing in particular in urban areas. They crystallize new forms of urban consumption as they constitute a link between the fast rhythms of urban life and the aspiration for specification and differentiation of oneself through food consumption (ASCHER 2005).

Rather than being a radical innovation, quality fast food development in Paris can be understood through the concept of path plasticity. That is innovation and change occurring within a well-established institutional setting of technology/knowledge development path (Paris catering services in our case) without necessarily breaking out of the path in question. Path plasticity is an alternative way for innovation to develop through knowledge combination, continuity and dynamic change rather than the classical process of creative-destruction (STRAMBACH 2010). Quality fast food has developed relying on the existing structures of the catering produc- tion system but at the same time it has created bridges between two kinds of restaurants: traditional (for the research on taste and fine cuisine) and fast food (for the way of eating).

This paper questions the conditions of the emergence of this new form of catering in Paris. It questions the knowledge dynamics underlying the emergence and development of these places which are often located in cultural/touristic or trendy areas. How is the articulation between gastronomy/design/fast food/culture organized? How quality is actually constructed through the creative (re)coordination of production and consumption activities? How does the relational and institutional path plasticity of territory enable creative knowledge use, generation and combination according to a new socio-economic construction of quality?

In the following the way this innovation emerged is outlined. The first part presents some considerations on the nature of innovation in what we may call here the creativity paradigm. The second part analyses the emergence and the evolution of quality fast food in Paris with regard to the relational and institutional path dependence and path plasticity in which it has been developing. Finally the notion of path plasticity is discussed along with this particular case study which opens to further research issues related to evolutionary construction of quality. 


\section{Understanding innovation dynamics in the context of the creativity paradigm}

\section{From technology in path dependency to crea- tivity in path plasticity}

Territorial innovation models (TIM) developed in the 1980s and 1990s (MOULAERT/SEKIA 2003) have pointed to the particular actor relations or institutional configurations underlying the development path of specialized production systems. They have mainly built upon an industrial and manufacturing approach expressed in terms of technological innovation, deduced from market changes or induced by scientific research. In the former case, regional competitiveness is determined by the specialized flexibility of a particular local production system able to adapt with an ever more changing demand (SimMie 2005). In the latter case, regional competitiveness is the result of the successful local development, transfer and implementation of a new cutting-edge technology into new products or production processes (CASTELLS et al. 1994).

These original TIM have emphasized the endogenous Marshalian dynamics of learning driving the local specialization of economic activities. They have showed how spatial proximity can enhance knowledge diffusion (e.g. through spin off and spill over) and cumulative learning processes within particular sectors and regions (Crevoisier/JeanNerat 2009). In such an approach, regional economy mirrors particular industrial and technological trajectories marked by historical, relational and institutional path dependencies (GrabHeR 1993; BoSHMa/LAMBOOY 1999; OINAS/MALECKI 2002) as well as by stabilized cycles of development and production (e.g. emergence, growth, decline, adaptation, restructuration).

Over the past decade, important literature has balanced this techno-scientific approach with new concerns regarding the growing importance of immaterial factors in economic development. Therefore, various works have pointed to the rise of knowledge-based economy and of knowledge-based services to advocate the need of getting beyond industrial, sectoral or technological paths to understand more permanent, more complex and more open innovations (see for instance, Strambach 2008; CoOKe et al. 2006; Foray 2004; Chesbrough 2006; Martin/ SUNLEY 2007). Other studies have emphasized the determinant place of cultural resources and activities (LAZZERETTI 2012; CoOKe/LazZEReTTI 2008; Kebir/Crevolsier 2007; Power/ SCOTT 2004) in the economic development of a postmodern society increasingly driven by the symbolic value of goods and services (HARVEY 1989). The concept of the creative economy was progressively established in literature to encompass these cognitive and cultural aspects of economic and territorial development. On the one hand, it points to more cross-cutting and project-oriented learning processes taking place across sectors, industries and regions and within shorter and adaptive life cycles (GRABHER 2002; QVORTRUP 2006; AsHeIM et al. 2011). On the other hand, it also designates a more systematic and strategic exploitation of cultural activities in economy (COOKE/LAZZERETTI 2008; GARNHAM 2005).

Contrasting the notions of path plasticity and path dependency in this special issue reflects in many aspects what we may see as a shift from a technological to a creativity paradigm (Tab. 1). While path dependency points to the particular historical, relational, institutional conditions shaping the cumulative trajectory of economic change, path plasticity seeks to explain how these same conditions may enable a creative combination of new external resources and a resilience of the original production system, rather than its radical change (StRAMBACH 2010, see also Strambach/Halkier in this volume). In other words, path plasticity allows innovations at the margin of an existing production system through creative forms of hybridation between activities a priori opposed (e.g. a cross-fertilization of fast food and traditional cuisine competences).

From a territorial perspective, focusing the analysis on path plasticity rather than on path dependency leads to reconsider TIM. A primary research question is not merely to depict how a local heritage (historical knowledge, culture or industry) is exploited by regional actors to produce a competitive offering. It is also to identify how this heritage can become a pool of specific resources upon which projects can develop (GRABHER 2002). In this view, a region is perceived as a creative project arena (QVORTRUP 2006) and cross-sectoral platform (ASHEIM et al. 2011) anchored in multi-local relations (CREVOISIER/JEANNERAT 2009), rather than a specialized innovation system within a global market.

Creativity for what quality? While the notion of path plasticity converges in many aspects with 
Tab. 1: The main features of technological and creative paradigm

\begin{tabular}{|c|c|c|}
\hline & Technological paradigm & Creativity paradigm \\
\hline Knowledge bases & Analytic-synthetic & Symbolic-analytic-synthetic \\
\hline Innovation driver & Techno-science & Creativity \\
\hline $\begin{array}{l}\text { Territorial knowledge } \\
\text { dynamics }\end{array}$ & $\begin{array}{l}\text { Regional trajectories of cumulative } \\
\text { knowledge dynamics }\end{array}$ & $\begin{array}{l}\text { Multi-local ad hoc processes of know- } \\
\text { ledge generation, use and combination }\end{array}$ \\
\hline Temporality & Long and stabilized trajectories & Short life cycles and continuous renewal \\
\hline $\begin{array}{l}\text { Evolutionary path of } \\
\text { innovation }\end{array}$ & Path dependency & Path plasticity \\
\hline $\begin{array}{l}\text { Conception of market and } \\
\text { quality in innovation }\end{array}$ & $\begin{array}{l}\text { Market as exogenous selection/informa- } \\
\text { tion mechanism in economic change } \\
\text { Quality given by technology }\end{array}$ & $\begin{array}{l}\text { Market as endogenous construct of eco- } \\
\text { nomic change } \\
\text { Quality co-constructed in production- } \\
\text { consumption processes }\end{array}$ \\
\hline
\end{tabular}

Source: own elaboration from JEANNERAT/CREVOISIER 2008 and JEANNERAT/KEBIR 2010

an increasing corpus of literature in economic geography dealing with creativity in regional development, we see in this concept an opportunity to open an additional questioning, namely the question of quality in market construction.

In the technological paradigm, quality is often conceived as given by the technological performance of a product or a production process. Explaining the economic value of technological innovation has thus often been restrained to an observed competiveness in the market, acting there as exogenous information and selection mechanism. If shifting from a technological to a creativity paradigm has enabled to shed light on complex learning processes taking place in the up-stream dynamics of innovation (research and development; supply chain relations) downstream relations in market construction (e.g. producer-consumer relation, market creation) have largely remained neglected (РЕCK 2005; LAGENDIJK 2006; GRABHER et al. 2008; BERNDT/ BOECKLER 2009). The economic value of creative activities has usually been supply-oriented (GARNHAM 2005) and is still resumed to an observed competitiveness.

Addressing path plasticity in economic and territorial development today should not only emphasize the socio-institutional conditions of competitive knowledge (re)combinations in production but also the conditions in which competitiveness is constructed. This implies considering market not as an exogenous selection and information mechanism, but as an endogenous construct in economic change (POTTS 2011). Market becomes, in this view, the uncertain context in which economic and non-economic actors coordinate themselves and assign value to products and services (BECKERT 2009).

Consequently, the quality of goods and services in a market is not given by technology or by creativity but results from a perpetual process of qualification and requalification undertaken by market actors (CALLON et al. 2002). Market qualification is the driver of market construction and economic competitiveness. It does not only involve a production system in which producers mobilize resources to provide a competitive offering by comparison and contrast with other products. It also involves a consumption system within which intermediaries and consumers dedicate particular resources to make these products visible, singular and comparable.

From an institutional point of view, market construction reflects quality conventions against which actor justify the comparison and differentiation of different products (FAVEREAU et al. 2002; BolTANSKI/THEVENOT 1991). Quality conventions are the purpose of negotiation, redefinition and legitimation within the production and consumption systems (JEANNERAT 2013). The tremendous role of the media in the diffusion of organic food consuming in France illustrates, for instance, the importance of this subsystem (eating organic was considered as alternative few years ago). Furthermore, consumers' involvement in innovation has become ever more relevant in many cases (software creation, short supply food chains) and has to be systemically analyzed as a constitutive element of innovation (RitZer/JuRgENSON 2010; Von HipPel 2005). 
From a territorial perspective, addressing creativity and path plasticity with regard to quality construction implies considering regional innovation not only in a production system able to adapt to consumer's demand or to create ingenious productive solution from new knowledge use, generation and combination. It is also considering territory as a quality system (HAUGE/ POWER 2013) whereby production and consumption processes participate to the construction of economic value and change.

The emergence of so-called quality fast food restaurants in Paris reflects the high symbolic knowledge intensity and knowledge variety characterizing the creativity paradigm described above. In the next section, we depict the particular evolutionary path dependency and plasticity in which this new urban offering has been developed. We show that innovation not only relates to new knowledge combination in production but also to definition and legitimation of new quality conventions rooted in the air du temps (Zeitgeist) of the international and Parisian urban lifestyle.

\section{Quality fast food restaurants}

The case study presented here is based on documentary research as well as on in-depth interviews with restaurant managers/founders (8) and with the fast food trade organization. These interviews were part of a broader research project on food consumption practices changes and their effect on production organization regarding in particular the role of producer-consumer relations. At the time of the interviews (2008) quality fast food supplies were not that developed in Paris. The interviewees were chosen according to the particularity of the concept they proposed to the client (e.g. organic food, local food, diet, chic/trendy food, diversity of services offered) and their (relative) longevity. The redundancy of the answers given by actors was used to determine the number of interviews ("snowball method", cf. PATTON 1990).

The case study analyzed production and innovation through the interrelations between the three subsystems of the economic system (JEANNERAT/ KEBIR 2010): the object system that encompasses all the material and immaterial elements used as resources (e.g. knowledge); the production system that encompasses the actors of e.g. production, firms, research centers, support agencies; the consumption system that encompasses all the actors and activities participating to the qualification and requalification of market goods by consumers such as distributors, retailers, media, experts, opinion leaders, bloggers, consumer groups, civil society, NGO, certifying/ labeling institutions.

This analysis allowed identifying the technical, socio-institutional and territorial dimension of this economic system. The technical dimension informs about the concrete aspects and contents of the investigated change process (e.g. the types of activities, knowledge and products involved in the creation and valuation of the new offering); the socio-institutional dimension emphasizes the type of actors and their forms of coordination in the production, qualification and consumption of the new offering. The territorial dimension points to the spatial and temporal dimension of the explored change process. It considers the proximity/distance relations of knowledge dynamics and their anchoring in the urban milieu of Paris. Finally, the evolutionary paths (dependency and plasticity) in the production as well as in the new qualification of the offering were described with regard to the evolution of urban catering and food consumption.

\section{2: opening of the first fast food restaurant in Paris}

The emergence in the years 2000 of quality fast food restaurants can be described as the combination of two tendencies: the development of fast food which comes in line with changes in the eating habits ${ }^{2}$, and with the quest for healthy, tasty and diversified lunch food. As observed by FANTASIA (1995), fast food restaurants appeared in France in 1972 with the opening of the first McDonald's followed by other American chains. Between 1972 and 1976, many French fast food restaurants developed on the American model. From 1976 some entrepreneurs started to develop fast food restaurant à la française selling traditional French food (e.g. viennoiserie, croissanteries, sandwich places) together with marketing, restaurant designs and production processes typical of American fast food (FANTASIA 1995). After this first phase of fast food emergence, the 1980s witnessed an expansion of this second type of restaurants and a vertical integration of the sector.

In this context, the recent emergence of quality fast food restaurants appears essentially as a 
niche market in the whole restaurant industry sector. Observed in other metropolitan areas such as New York and London, the concept was imported and developed by individual pioneer entrepreneurs. These restaurants have now spread around the city. Nevertheless, their amount still remains a very small proportion of French fast food restaurants.

The official first quality fast food restaurant opened in 1989. Since then, two of the three cofounders have launched their own business and several of such restaurants have opened in Paris, particularly in the city center. A guide has been published "Bien manger sur le pouce à Paris" " "To have a good quick bite to eat in Paris") (PonCEBlanc et al. 2006). It lists more than a hundred of similar places. Most of them remain single. Some have started to develop into a chain. The business is not easy, customers have a very wide choice, renting prices are very high especially in the city center which is the main market place. As we will see owners find their ways motivated by self-satisfying work, food they love, and a sense of business that they often have acquired in former jobs in knowledge intensive business services (e.g. finance, KIBS in food industry, advertisement). In France no specific diploma or license is required to open a restaurant. This allows newcomers into the ca-

Fig. 1: The evolutionary path of fast food in France

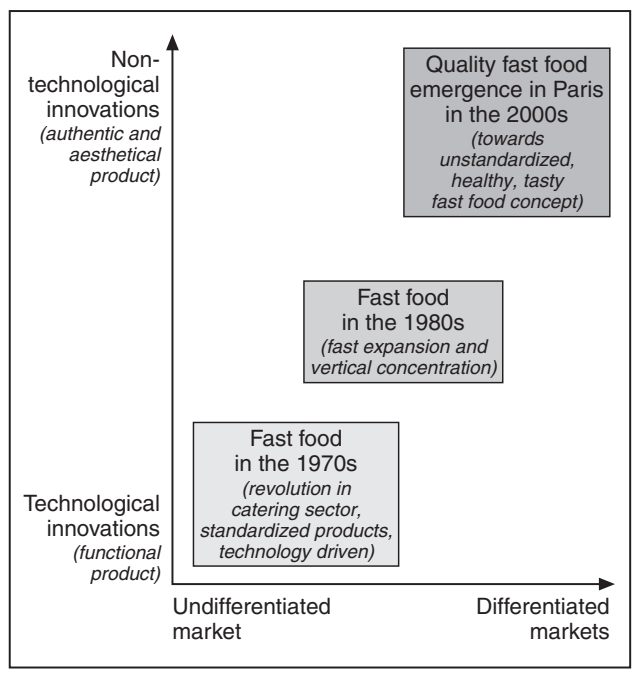

Source: own elaboration from JEANNERAT/CREVOISIER (2011) tering system; in particular, from other production sectors.

\section{Quality fast food as an innovation: the technical dimension}

About quality fast-food: There isn't any term or concept broad enough to catch the variety of quality fast food today. As an emerging form of food place, these restaurants do not constitute a stable and coherent ensemble yet. For example, the guide mentioned above speaks e.g. about sandwich places or snack chic. If all these places do have a fast dimension influencing the business organization (opening hours, work organization, type of food served, kind of service provided), not all of them are legally designated as fast food restaurants. In France, the official statistical classification of economic activities (NAF code) distinguishes between classical and fast food restaurants. ${ }^{3}$ According to the official definition, fast food restaurants gather the activities providing food and beverage in disposable packaging at the counter to be eaten on the spot or to be taken away. ${ }^{4}$ This definition contains classical fast food chains (e.g. McDonald's, Pizza Hut, Quick Lunch), ethnic fast food (e.g. sushi places, kebab) and all other kinds of sandwich retailers, among which quality fast food providers can be found. Conversely, other investigated restaurants are officially considered as classical restaurants because they deliver food at the table and/or serve it in non-disposable dishes.

If distinguishing empirically quality fast food restaurants from classical fast food is rather uncomplicated, defining what quality is, is not evident and a matter of the point of view. Quality fast food restaurants can serve e.g. hot dishes, cold dishes, sandwiches, soups, salads. In this sense what differentiates them is more the concept than the type of dish served; a concept based on unstandardized, fresh, diet friendly and/or tasty fast food. The issue is therefore clearly one of the creativity paradigm were producing and selling concepts are fundamental (in contrast to the technological paradigm based on market goods). The concept developed by the producer/ founder of the restaurant embodies in the food served and in the quality coproduced with the consumer. As Nelson (1970) and DARBY/KARNI (1973) explain, if some aspects of quality can be anticipated by the consumer and controlled by the producer before eating (e. g. search characteristics: color of the food, size of products) other aspects of quality also rely on personal 
experiences (experience characteristics: taste) and beliefs (credence in particular characteristics: such as the ecological or health conditions of the food production). The consumer is therefore a full participant of the quality creation and valuation. Following BRUNSø et al. (2002, 11) consumers' expectations in terms of food quality have four dimensions:

- taste refers to the pleasure/hedonic aspect of food,

- health refers to how food will affect one's health,

- convenience refers to the easiness of handling the food, the expected time and energy (physical and mental) saved in the meal process when buying the food (easiness of preparation - ready-to-eat food, pre-cooked meal - storage),

- process refers to the way the food is produced (environmental friendliness, animal welfare).

These four dimensions are not independent but interrelated in different ways according to the food offering (the concept). For instance, good taste/smell can be associated to health (eggs, meat). Quality fast food restaurants mainly position themselves in contrast to standard fast food by valuing health (less fat, balanced meals according to nutrition standard) and processes (fresh, eventually organic/fair trade products and home-made meals). Taste is for sure a central element of quality. However, it does not provide fundamental differentiation among market offerings (no restaurant will ever claim selling bad taste food). In fact, the dish served can be quite sophisticated in terms of taste/product combinations research.

If quality fast food restaurants represent a very small number of fast food restaurants, their number is increasing (as the overall fast food sector). Most of them crystallize new forms of urban consumption and constitute a link between the fast rhythm of urban life and the aspiration for individual specification and differentiation through food consumption (ASCHER 2005). As a service they contribute to the urban amenities, to the trend setting and to the creative atmosphere of Paris. This is particularly interesting for many people working in knowledge intensive business services (DOLOREUX/MATTSON 2008; SimMIE/ STRAMBACH 2006) which constitute the main market for these restaurants.

Path dependence in technical innovation: From a technical perspective, innovation in the Pari- sian quality fast food is driven by the capacity to link the easiness of fast and fine taste/diet friendly quality food. They are proposed as a market alternative to standardized and unhealthy fast food, to formal traditional restaurants, to firm canteens and to the traditional cafés that used to be one of the main snack food providers ${ }^{5}$ (e.g. they serve croque monsieur, baguette sandwiches, hot dogs). The service provided includes three dimensions. The first and fundamental aspect is the meal and the food served. Much attention is given to the food: quality, hygiene, taste, diet, aesthetics. This is the core business. One could have expected more emphasis on the setting of additional services (e.g. wireless internet connection, magazines, book access, sound atmosphere). This primary focus on food can be explained by the fact that these restaurants develop as an alternative to classical fast food. They are therefore built first of all upon the food project. Of course, stage setting is a determinant part of the concept. However, even if refined and conceived by trendy designers, it remains driven by the food project. The experience dimension (PINE/Gilmore 1999) of food, especially when food quality is put forward, still constitutes, for the owners, the basis of the product - as in restaurants in general. If additional services are offered (wireless internet access, newsletter or advices to the consumers) it is the offered food that is primarily qualified by market actors (e.g. the attribute of food, its price or the selected raw materials).

In terms of production organization, actors rely on the catering production system which is very organized, structured and developed in Paris. The Rungis International Market (main food supplier), the existence of equipment firms provide specialized services to restaurants according to their needs (late orders for the next morning for example). Owners also collaborate with design firms, webmasters (many of these restaurants have a web page) and some also rely on editing companies (when they have their own paper and electronic newsletter). These relations can carry knowledge exchange. Either through specific projects (the design of the restaurant) or on a more everyday base (food providers seeking for the specific products wanted by the chef or suggesting new ones).

As mentioned, food providing remains the core business. The concept at the fundament of the market offering and of business is an interesting articulation of the personal/professional experi- 
ence trajectory of the suppliers (determining) and of their capacity to capture and meet the air du temps or zeitgeist $t^{6}$ expressed by the urban demand. For instance, eating organic, not standardized and healthy food has generously been promoted in the media since mid 2000. After the successive food crises, one is no longer awkward to eat organic food.

The restaurant's concept materializes in the menu, which might evolve through some forms of consumers' education to certain diets or ingredients (some special dishes or ingredients are introduced progressively in order to avoid creating a rupture in consumers' habits). The communication on the ingredients and the content of the dishes appears quite central, even though consumers are not necessarily connoisseurs. ${ }^{7}$ Also, information on the provenance and on the quality of the products (e.g. organic, fair trade labels) is often indicated. The importance being that consumers can know what they eat if they wish. Quality here relies on the dishes and on the service offered. The producer-consumer relations remain mainly producer-driven in the sense that it is still the producer who initiates consumer learning and who integrates eventual remarks made by consumers (e.g. maintaining of certain dishes on the menu over time, critics on the ingredients) and by giving them the opportunity to discover new ingredients or types of dishes. The balance between the audacity of the producer and the taste susceptibility of consumers is an on-going process that is mainly in the hand of the former. The consumers as we said vote with their (light) feet.

Path plasticity in knowledge intensive innovation: A central issue in the emergence and in the development of the innovation of quality fast food relies upon the creative combination of new knowledge resources. The access to a high diversity of fine raw ingredients and to equipment is not itself an issue. The supplying system of restaurants is well structured, well organized and well-furnished in Paris. Finding a good strategic location for the restaurant is more challenging as restaurants need to be close to their potential customers (high qualified workers), mostly situated in expensive quarters. Again this issue is quite classical and not new in Paris. What appears to be more specific in our case are the efforts made by actors to combine various types of knowledge in the development of a new hybrid restaurant industry (Fig. 2).

AsHEIM et al. (2007) distinguish three forms of knowledge: the analytical knowledge, which stems from fundamental research and which is codifiable; the synthetic knowledge, which is about finding solutions to concrete problems, and which articulates codified and tacit knowledge (engineer science, applied knowledge and experience); the symbolic knowledge which is about creating symbolic value (aesthetics, design, images, concepts) and sense building, and which relies on culture and creative activities. As seen in the case study, market food offering is about nourishing as well as providing experience and pleasure to customers. Led by the owner and the chef (it can be the same person or a consultant), these two dimensions of the product principally buildt upon synthetic and symbolic knowledge. Synthetic knowledge here concerns cooking skills and business skills (mastering the codes of both fast food and traditional restaurant industry). Symbolic knowledge relates to inspiration, aesthetics, and capacity to anticipate what will be appreciated by customers and to build sense (concept creation) around the food pro-

Fig. 2: The three dimensions of the product offered and the type of resource mobilized

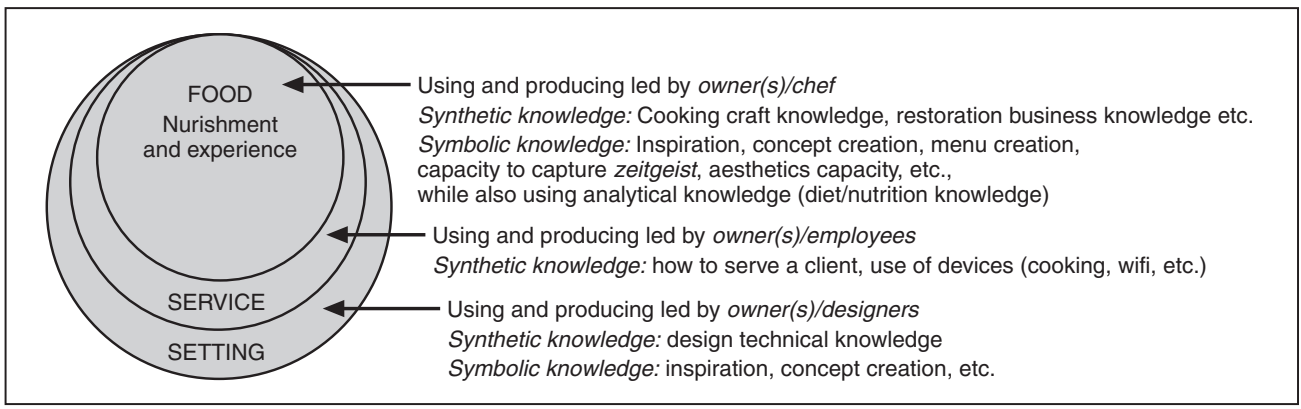

Source: own elaboration 
ject. Mixing together both types of knowledge is here at the root of innovation. We should also mention analytical knowledge dynamics in the field of diet and nutrition driven by a search for coherence with symbolic value of the concept promoted by the restaurant.

Remaining in the fast food heritage, the service dimension is quite restrained. Held by the owner and the employees, the knowledge mobilized and reproduced here is synthetic (e.g. how to serve clients, explain/give advice on the menu, to use the multiple devices present from cooking devices to the internet wireless installation).

As a third dimension, setting is conceived from the beginning of the project. It is part of the offered food concept. It includes the setting of the restaurants itself but, in most cases, also the web page explaining the concept and providing all kinds of information on the restaurants. Led by the owner, or eventually by sub-contractors, setting asks for synthetic knowledge related to the technical design of the restaurants. It also requires symbolic knowledge in the creation of the concept. Setting finally implies media knowledge dedicated to web mastering, web editing and in some cases print editing.

The development of the three dimensions of the product implies both the use and the renewal/development of existing knowledge. For instance cooking implies skills and know-how acquired through learning by doing (owners often cook themselves at the very beginning) or by regular training (chefs hired at the beginning or when the business increases). Seeking to offer alternative food (vegetarian, special ingredients, organic food, light dishes) chefs and cooks often need to adapt their competences to the owner's concept and menus. For instance, the concept of self-service fast food is that consumers pick their dishes (sandwich, salad, cake) out of others similar ones. This implies that all the dishes have to look the same (same size, same amount of avocado in the salad, same spillover of tomato in the sandwich) and it requires from the cooks a nearly industrial regularity (the dishes are usually assembled/prepared fresh on the spot or in the central kitchen of the restaurant's chain). This is quite different from classical restaurants where slight differences between each plate are considered as a proof of craftwork (in contrast to industrial preconditioned food). Quality fast food restaurants adapt this constraint to their specific meal offering (as compared to regular fast food).

\section{The emerging quality fast food: a blurred network of actors}

Actors involved in quality fast food innovations are numerous and intervene in different circles of action and relations (Fig. 3). The frontiers of each circle are not clearly determined and the network of actors remains blurred.

A first circle of players involves the restaurants themselves, the providers of the regional restaurant industry productive system (food, equipment, packaging suppliers), the SNARR (the chef industry trade organization). If the restaurants can weave co-operative forms of relations with their suppliers, no similar relations have been observed among restaurants themselves. They all know each other but keep distance as they also compete which each other. Most of them are still small businesses. Quality fast food being an emerging sub-sector, it has neither the size nor the means (the needs?) for institutionalized cooperation yet.

A second circle of actors contains creative services dedicated to the promotion of the restaurant and its food concept (internet, design, editing). The relations among these actors are more punctual, project oriented and product specific. They are often based on former network relations. Consumers do not intervene much in the production of the service (they rarely ask for specific products or ingredient characteristics).

Fig. 3: Actors of the quality fast food system

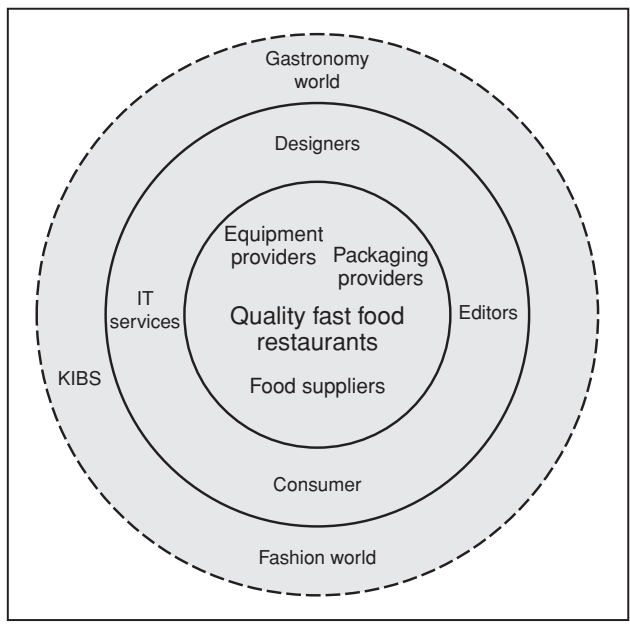

Source: own elaboration 
However, they vote with their feet and thus require constant attention (e. g. service quality). As mentioned before, targeted consumers are welleducated and well-paid urban workers. Some restaurants, because of their location, may also attract tourists. Nevertheless, they mainly rely on the loyalty of a regular group of consumers working at proximity. The word of mouth plays a decisive role in the promotion of the restaurants.

A third circle, further in terms of density of relations, involves what could be named the incubatoring services. On the one hand, workers in knowledge intensive business services (KIBS) are the main potential customers of quality fast food restaurants. On the other hand, these same actors constitute the incubators of restaurant founders (the case study has showed several cases of workers who have quit their former jobs in advertisement or financial services to create a quality fast food restaurant). Actors of the restaurant/food world (including fast food classical restaurants) also appear as incubators of restaurant founders. Creating a quality fast food is for the latter a way to diversify their experience and a way to follow their carrier path. Such kind of restaurants is, in many aspects, easier to manage than traditional restaurants. It is in line with ongoing trends of gastronomy. It is quite usual today to see renowned chefs opening new restaurants combining the quality conventions of fast food and gastronomic restaurants. The last group of actors of this third circle originates from the fashion world in which we include women magazines. These actors contribute to the co-production, legitimation and diffusion of air du temps/ zeitgeist, which inspires the creativity of restaurant owners and chefs (concept and menu creation). The frontiers of this circle are left open as its limits are very blurred and moving.

The development of quality fast food thus mixes actors from different realms of production: of restaurant industry, of agriculture, of creative industries and of KIBS. It mixes various experiences and knowledge bases (STRAMBACH 2008). Apart from the chef industry trade organization, public actors or institutions did not appear much present in the development of the restaurants. Nevertheless as in all restaurants, the legal context is rather structuring as it notably frames quite precisely the organization of the kitchen (for hygiene and food sanitary matters). Indirectly, public actors are in this sense quite present.

\section{Territorial dimension of quality fast food innovation}

The core of the economic system of quality fast food is located in the Paris region. Even though most objects and resources (food products, devices, specific knowledge such as designing) come from outside the region, the production process is primarily local as main actors are located in Paris (quality fast food restaurant rely on the local catering industry). The consumption system is also local. First of all, the customers are mainly workers from the region or temporary visitors. The media, fashion industry that contributes to the evolution of the system are de facto located in Paris. Nevertheless, local actors are able to tap specific resources (symbolic knowledge) outside the region when necessary. For instance, an internationally renowned designer living in Tokyo and Paris was hired to conceive the setting of one of the studied restaurants. The consumers, mainly workers from knowledge intensive businesses) are also located inside the region. More generally this metropolitan character of the territory appears as central for the development of quality fast food: It provides consumers and it is a node for knowledge circulation from worldwide and knowledge anchorage in Paris. In particular it connects to the territory of inspiration and of diffusion. This territory encompasses the actors of the restaurant/food world and those of the fashion world. These actors can be located in Paris, of course, but also come from other places.

Quality fast food was imported from London and New York City by persons who identified the market opportunity for such restaurants in Paris. This worldwide territory has very blurred frontiers. Interviewed actors themselves found it difficult to specify the origin of their inspiration, among them magazines, books, trips abroad, interaction with peers. The metropolitan characteristic of Paris certainly acts as a platform or gateway to the symbolic knowledge circulating in this territory (e.g., through the fashion magazines that are produced in Paris). The issue here for quality fast food actors is to be connected to this world and to be able to catch the air du temps, the trends that should be introduced in their own projects and market offering. The anchoring of this new activity relies in the urban-metropolitan character of Paris that provides the market, the suppliers, the services and the connection to the inspiration and diffusion world. As such the territorial conditions have been fundamental to the emergence of this new form of catering. 


\section{Conclusion}

The development of quality fast food restaurants combines the codes of traditional and fast food restaurants. In this sense, it appears as a hybrid form of restaurants. Originating from the old and well-structured catering industry of the Paris region, it is developing in some sort of continuity (there is no path rupture), in line with the global evolution society's food practices. Quality fast food restaurants rely on the resources of the catering system while developing new concepts and ways of producing meals. In terms of knowledge dynamics, we observed both knowledge accumulation and combination. Reputation, cooking and catering skills, which are related to knowledge accumulation, play a crucial role in the success of these projects and more particularly in the interaction at distance with other actors (possibility of working with a trendy designer or a renowned chef). The fact that no diploma or license is required to open a restaurant certainly provides plasticity to the catering system. In our case, the newcomers brought with them their business experience, expertise and networks, which helped developing a new market.

Knowledge combination appears here as fundamental and is at stake at two levels: first, in the mixing of traditional and fast food restaurant skills and know-how; second, in the combination of cooking practices (crafted, home-made, fresh and unstandardized food production) and catering constraints (labor costs, work organization, stocks management). The main actors of knowledge combination are the owners/chefs for whom it is one of the core competencies. Fast food meals are multi-dimensional. They combine commodities, goods, services and experience production. Commodities, goods and service production rely on cumulative knowledge dynamics, whereas more symbolic tasks such as concept creation (menu creation, setting, design) are more subject to experience, trends and fashion. More punctual collaborative activities rely on combinatorial dynamics that go beyond the frontiers of the region. They thus develop according to the creative paradigm mentioned earlier.

Quality fast food restaurants do not just provide meals; they provide a food concept, thought over and elaborated according to the inspiration and the objectives of the owner. The demand is not yet formalized, clearly expressed. It is merged in the zeitgeist that owners/chefs capture and interpret through their concept of food and of restaurant, in this context quality co-constructed with intermediaries (e.g. services of the second circle) and the consumer. The emergence of quality fast food restaurants requires new forms of quality conventions (what are the means for health and convenience quality?).

Quality fast food found their place in the restaurant landscape of Paris and, in the years to come, will certainly continue to develop. Mixing the codes of two opposed forms of restaurants will surely be a key in the success of the economic system of quality fast food. However, let us not forget that what is called quality today should not be taken for granted.

\section{Notes}

1 This paper presents some of the results of a research undertaken under a fellowship from the Swiss National Science Foundation at UMR SAD-APT/INRA, France. These results were part of the EURODITE FP6 project.

2 Fantasia $(1995,205)$ identifies five factors as being important in the evolution of eating habits in France: "1) the growing of women in the paid labor force $(\ldots) ; 2$ ) increases in the spendable income of young adults; 3 ) a weakening of family ties placing less emphasis on family mealtimes; 4) the expansion of the journée continue in the workplace (the working day without extended meal breaks) creating a need for both fast food and workplace catering systems; and 5) increased urban traffic congestion, which prevents workers form travelling home and back, forcing workers to take their meals in the city." These changes have also contributed to the development of institutional food (e.g. canteens) and agro-industrial processed food.

3 The statistical classification of economic activities in the European Community (NACE code) doesn't make such a distinction as there is only one "restaurant" category (55.30). As such the French classification goes further than the European.

4 Fast food restaurants according to the French statistical classification (NAF) also encompasses trolley ice cream selling, meal selling with mobile equipment and meal preparation on stalls or on markets. It includes tea houses but not the selling of food and beverage in vending machines.

5 Cafés have been going through hard times in Paris for the last past years (e.g. difficulties of transmission for retiring owners, difficulties to meet new consumption trends, high prices).

6 We make here the choice to speak of zeitgeist or air $d u$ temps even though acknowledging the "structuralist" sense both may have. Schematically ERNER (2009) identifies two major conditions of emergence of fashion trends. One rather top-down, with the idea that each period of 
time would have a sort of essential spirit that embodies notably in the symbolic dimension of the surrounding objects (BARTHES 1957). It therefore exists an implicit demand related to this spirit. Some actors capture this implicit demand and launch new trends cycles that percolate all through society, from fashion itself to other realms of activities. This process is collective and beyond individuals. The second approach, somewhat bottom-up, defends the idea that consumers, as individuals, do not necessarily behave as expected (otherwise there would not be trend failures) and also that trends rather develop according to auto-prophetic processes (MERTON 1997). As such if some known and recognized top model, pop star or brand promotes some specific cloth or behavior, they are imitated and the "prophecy" realized (this object or behavior being potentially trendy or fashionable actually becomes trendy and fashionable). In our case we refer to the first approach. The owners of the restaurants develop their activities in a context already defined, even if some were real pioneers in quality fast food development, they rather benefit from already existing "in the air" demand.

7 We find here the same process as described by JEANNERAT (2013) in the watch industry, that is the necessity for the consumer to have a minimum knowledge base on the product to understand/perceive its value. The process of learning can happen in many different ways, either through self-teaching, through information/training provided by the seller or through the media and interpersonal networks.

\section{References}

AsCHER, F. (2005): Le mangeur hypermoderne. Une figure de l'individu éclectique. Paris.

Asheim, B. / Boschma, R. / Cooke P. (2011): Constructing regional advantage. Platform policies based on related variety and differentiated knowledge bases. In: Regional Studies, (45)7, 893-904.

Asheim, B. / Coenen, L. / Moodysson, J./ VAng, J. (2007): Constructing knowledge-based regional advantage: implications for regional innovation policy. In: Journal of Entrepreuneurship and Innovation Management, (7)2-3-4-5, 140-155.

BARTHES, R. (1957): Mythologies. Paris.

BECKERT, J. (2009): The social order of markets. In: Theory and Society, 38, 245-269.

BERNDT, C. / BOECKLER, M. (2009): Geographies of circulation and exchange. Constructions of markets. In: Progress in Human Geography, 33, 535-551.

BOLTANSKI, L. / THÉVENOT, L. (1991): De la justification, les économies de la grandeur. Paris.

Boschma, R.A. / Lambooy, J. G. (1999): Evolutionary economics and economic geography. In: Journal of Evolutionary Economics, 9, 411-429.

Brunsø, K. / Fjord, T.A./Grunert, K. G. (2002): Consumer's food choice and quality perception. Aarhus. (Aarhus School of Business, working paper No. 77, June 2002).

Callon, M. / MÉadel, C. / Rabeharisoa, V. (2002): The economy of qualities. In: Economy and Society, 31, 194217.
Castells, M. / Hall, P. (1994): Technopoles of the world. London / New York.

Chesbrough, H. (2006): Open business models. How to thrive in the new innovation landscape. Boston.

Cooke, P. / Lazzeretti, L. (2008): Creative cities, cultural cluster and local economic development. Cheltenham, UK/ Northampton, USA.

CoOKe, P. / LeydesdorfF, L. (2006): Regional development in the knowledge-based economy. The construction of advantage. In: The Journal of Technology Transfer, 31, 5-15.

Crevoisier, O./JEAnNERAT, H. (2009): Territorial knowledge dynamics. From the proximity paradigm to multilocation milieus. In: European Planning Studies, 17, 12231241.

DARBY, M.R. / KARNI, E. (1973): Free competition and the optimal amount of fraud. In: Journal of Law and Economics, 16, 67-88.

Doloreux, D. / MAtTSOn, H. (2008): To what extent do sectors "socialize" innovation differently? Mapping cooperative linkages in knowledge-intensive industries in the Ottawa region. In: Industry and Innovation, (15)4, 351-370.

ERner, G. (2009): Sociologie des tendances. Paris.

Fantasia, R. (1995): Fast food in France. In: Theory and Society, (24)2, 201-223.

FAVEREAU, O./BIENCOURT, O./ EyMARD-Duverney, F. (2002): Where do markets come from? From (quality) conventions! In: Favereau, O. / Lazega, E. (Eds.): Conventions and structures in economic organization. Markets, networks, and hierarchies. Cheltenham, 213-252.

ForAY, D. (2004): The economics of knowledge. Cambridge.

Garnham, N. (2005): From cultural to creative industries. An analysis of the implications of the "creative industries" approach to arts and media policy making in the United Kingdom. In: International Journal of Cultural Policy, 11, $15-29$.

GraBhER, G. (1993): The weakness of strong ties: The lockin of regional development in the Ruhr area. In: Grabher, G. (Ed.): The embedded firm. On the socioeconomics of industrial networks. London, 255-277.

GrabHeR, G. (2002): The project ecology of advertising. Tasks, talents and teams. In: Regional Studies, (36)3, 245 262.

Grabher, G. / IBERT, O. / Flohr, S. (2008): The neglected king. The customer in the new knowledge ecology of innovation. In: Economic Geography, 84, 253-280.

HARVEY, D. (1989): The condition of postmodernity. Oxford.

Hauge, A. / Power, D. (2013): Quality, difference and regional advantage. The case of the winter sports industry. In: European Urban and Regional Studies (forthcoming).

JEANNERAT, H. (2013): Staging experience, valuing authenticity. Towards a market perspective on territorial development. In: European Urban and Regional Studies (forthcoming).

Jeannerat, H./ Crevoisier, O. (2011): Non-technological innovation and multi-local territorial knowledge dynamics in the Swiss watch industry. In: International Journal of Innovation and Regional Development, 3, 26-44. 
JeAnNerat, H./KeBIR, L. (2010): Economic systems of knowledge and regions. A typology based on the analysis of producer-consumer relation. London. (accepted and presented at the DRUID Summer conference, London 2010, Internet: http://www2.druid.dk/conferences/viewpaper.php ?id=501478\&cf=43).

KeBIR, L. / Crevoisier, O. (2007): Resources development and actors coordination. What role for innovative milieus? In: International Journal of Entrepreneurship and Innovation Management, 7, 204-222.

LAGENDIJK, A. (2006): Learning from conceptual flow in regional studies. Framing present debates, unbracketing past debates. In: Regional Studies, (40)4, 385-399.

LAZZERETTI, L. (Ed.) (2012): Creative industries and innovation in Europe. Concepts, measures and comparative case studies. London/ New York.

Martin, R. / Sunley, P. (2007): Complexity thinking and evolutionary economic geography. In: Journal of Economic Geography, (7)5, 573-601.

Merton, R.K. (1997): Elements de théories et de méthode sociologique. Paris.

MoulaerT, F. / SEKIA, F. (2003): Territorial innovation models. A critical survey. In: Regional Studies, (37)3, 289-302.

Nelson, P. (1970): Information and consumer behavior. In: Journal of Political Economy, 78, 311-329.

Oinas, P. / Malecki, E. J. (2002): The evolution of technologies in time and space. From national and regional to spatial innovation systems. In: International Regional Science Review, 25, 102-131.

PATTON, M.Q. (1990): Qualitative evaluation and research methods. Newbury Park/London/ New Delhi.

PECK, J. (2005): Economic sociologies in space. In: Economic Geography, 81, 129-175.

Pine, B. / Gilmore, J.H. (1999): The experience economy. Work is theatre $\&$ every business a stage. Boston.
Ponceblanc, J./Sorrel, J. (2006): Bien manger sur le pouce à Paris. Paris.

PotTs, J. (2001): Knowledge and markets. In: Journal of Evolutionary Economics, 11, 413-431.

Power, D. / ScotT, A. J. (Eds.) (2004): Cultural industries and the production of culture. London.

Qvortrup, L. (2006): The new knowledge regions. From simple to complex innovation theory. In: Cooke, P. / Piccaluga, A. (Eds.): Regional development in the knowledge economy. Abingdon.

Ritzer, G. / Jurgenson, N. (2010): Production, consumption, prosumption. In: Journal of Consumer Culture, 10, 13-36.

Simmie, J. (2005): Innovation and space. A critical review of the literature. In: Regional Studies, (39)3, 26-40.

Simmie, J./Strambach, S. (2006): The contribution of KIBS to innovation in cities. An evolutionary and institutional perspective. In: Journal of Knowledge Management, $10,26-40$.

Strambach, S. (2008): Knowledge-Intensive Business Services (KIBS) as drivers of multilevel knowledge dynamics. In: International Journal of Services Technology \& Management, 10, 152-174.

Strambach, S. (2010): Path dependency, path plasticity. The co-evolution of institutions and innovation - the German business software industry. In: Boschma, R. / Martin, R. (Eds.): The handbook of evolutionary economic geography. Cheltenham, 406-431.

Strambach, S. / Halkier, H. (2013): Reconceptualizing change. Path dependency, path plasticity and knowledge combination. In: Zeitschrift für Wirtschaftsgeographie, (57)1-2 (this vol.).

Von HipPel, E. (2005): Democratizing innovation. Cambridge, MA/London. 